\title{
3 Research Square \\ Predictors of perioperative blood transfusion and intraoperative blood loss in thoracolumbar tuberculosis
}

Shengyu Wang ( $D$ IKKI4640@126.com)

Second Affiliated Hospital of Harbin Medical University

Chao Liu

Second Affiliated Hospital of Harbin Medical University

Rongzhi Wei

Second Affiliated Hospital of Harbin Medical University

Qiuhua Zhang

Second Affiliated Hospital of Harbin Medical University

Feng Wu

Second Affiliated Hospital of Harbin Medical University

Yufu Wang

Second Affiliated Hospital of Harbin Medical University

Jinglong Yan

Second Affiliated Hospital of Harbin Medical University

\section{Research article}

Keywords: blood transfusion, intraoperative blood loss, risk factors, thoracic and lumbar tuberculosis

Posted Date: October 7th, 2020

DOI: https://doi.org/10.21203/rs.3.rs-84457/v1

License: (9) (i) This work is licensed under a Creative Commons Attribution 4.0 International License. Read Full License 


\section{Abstract}

Background. During surgery for thoracic and lumbar tuberculosis infection, patients can lose a significant amount of blood and thus require a perioperative blood transfusion. However, the risk factors for increased intraoperative blood loss and perioperative blood transfusion have yet to be identified. The aim of this retrospective study was to determine the predictors of perioperative blood transfusion and intraoperative blood loss in thoracolumbar tuberculosis.

Methods. From 2008 to 2018, 336 patients who met the inclusion criteria were enrolled in the study. The predictors of allogenic blood transfusion were identified using univariate and multivariate logistic regression analyses. Univariate and multivariate linear regressions were conducted to investigate the risk factors for intraoperative blood loss. The predictors of high levels of intraoperative blood loss were analyzed by multivariate logistic regression analysis.

Results. Altogether, 336 adult patients with thoracic and lumbar tuberculosis were included in this study. The mean age of patients was $49.6 \pm 15.5$ years old (range 14-85). Our data revealed significant relationships between blood transfusions and female gender, $\mathrm{BMI}$, vertebral collapse/kyphosis and intraoperative blood loss. Multivariable linear regression analysis revealed that BMI, levels of instrumentation, surgical approach and operative time were independent risk factors for intraoperative blood loss. Specifically, a lower BMI, decreased preoperative hemoglobin levels, four or more levels of instrumentation, a combined surgical approach and a prolonged operative time were identified as risk factors for high levels of intraoperative blood loss.

Conclusions. This study identified some clinical predictors of perioperative blood transfusion and intraoperative blood loss in patients undergoing thoracic and lumbar tuberculosis surgery. These results may contribute to the planning of preoperative blood transfusions and help to minimize intra- or postoperative complications.

\section{Level of evidence}

Level IV, retrospective case series.

\section{Background}

Subacute and chronic spinal infections are usually caused by a wide spectrum of pathogens, of which Mycobacterium tuberculosis is considered the most common.[1] The most common type of spinal tuberculosis is spondylodiscitis. In the last two decades, there has been a resurgence of tuberculosis in developed countries.[2] However, there are still challenges in the management of spinal tuberculosis.[3, 4] Surgical treatment is indicated for patients with infections that are resistant to antibiotic therapy or patients with bone destruction, kyphosis, neurologic impairment and severe pain[4-7]. Generally, debridement and bone grafting are the first choice of surgical procedures. $[8,9]$ 
Despite advances in surgical techniques, spinal tuberculosis is still associated with substantial blood loss, and many patients require a perioperative blood transfusion.[4, 10] Because tuberculosis is a systemic disease, the use of autologous blood transfusion is not recommended for such patients. In addition to issues regarding shortages and cost, allogeneic blood transfusion can be associated with serious complications and a prolonged operation.[11, 12] Thus, identifying patients at a high risk of intraoperative blood loss and those who are likely to require a perioperative blood transfusion is an important step to improve postoperative outcomes, reduce complications and minimize health resource utilization.[13-15]

To date, few studies have elucidated the risk factors for blood loss during spinal tuberculosis surgery. Research has also yet to identify which clinical factors predict the need for perioperative blood transfusion and blood loss in patients undergoing debridement and reconstruction procedures. Therefore, the objective of the present study was to identify predictors of high intraoperative blood loss and the need for perioperative blood transfusion from our series.

\section{Methods}

This study was approved by the university review board. A total of 336 patients with thoracic and lumbar spinal tuberculosis who underwent surgery were identified from two independent hospitals between January 2010 and November 2018. The diagnosis of spinal tuberculosis was based on the following previously reported criteria[10,16]: clinical manifestations, radiological evidence, response to antimicrobial therapy and results of microbiological examination. Indications for surgery included vertebral collapse and spinal instability; severe kyphotic deformity or progressive worsening of kyphosis; spinal cord compression by abscess or necrosis; formation of a hollow or sequestrum; or no improvement in antimicrobial therapy. The study population consisted of patients $>18$ years old. Patients with recurrence at the lesion site and who underwent deformity surgery without debridement were excluded.

The variables extracted for analysis included patient age, gender, preoperative hemoglobin levels, body mass index (BMI), location of the lesion (thoracic, thoracolumbar, lumbar or lumbosacral spine), vertebral collapse or kyphosis, discitis involved, levels of instrumentation, paraspinal/epidural abscess, surgical approach (anterior, posterior and combined procedure), operative time, the amount of intraoperative blood loss and the need for allogenic blood transfusion. The recorded intraoperative blood loss was obtained from the anesthetist's case records and confirmed by surgeons. Blood loss was further assessed using the electronic records in the institutional database. A blood loss of over $30 \%$ of the total blood volume during surgery was set as the cutoff for high levels of intraoperative blood loss. The total blood volume was calculated according to a previously reported method. [15] [17] The surgical procedures were classified into three categories. The anterior approach was performed by anterior or lateral-anterior debridement, autologous or allograft bone graft and instrumentation. The posterior approach was performed by posterior debridement, autologous or allograft bone graft and instrumentation. The combined approach was performed by posterior instrumentation combined with anterior debridement and autologous or allograft bone graft. 


\section{Statistical Analysis}

The independent factors used for prognostic modeling analysis were measured using either categorical or continuous variables. The logistic regression model was used in the univariate or multivariate analysis to identify the predictors of perioperative blood transfusion. To estimate the effect of different factors on intraoperative blood loss, both univariate and multivariate linear regression analyses were performed. The level of significance was set at 0.05 in all analyses. Statistical analyses were performed using IBM SPSS statistical software (version 23.0, Armonk, NY, USA).

\section{Results}

\section{Patient Demographics and Clinical characteristics}

A total of 336 patients with thoracic and lumbar tuberculosis who underwent surgery were evaluated for this study. The mean age of the patients was $49.6 \pm 15.5$ years old (range 14-85). There were 178 female and 158 male patients, and the mean preoperative hemoglobin level was $122.04 \pm 17.37 \mathrm{~g} / \mathrm{L}$.

Perioperative blood transfusion was performed for $66.1 \%$ of the patients. A total of $11.3 \%$ of patients (38) had high intraoperative blood loss during surgery. For the entire cohort, the mean intraoperative blood loss was $661.37 \pm 557.54 \mathrm{ml}$. The mean blood loss was $832.13 \pm 590.17 \mathrm{ml}$ for the patients who received a blood transfusion and $276.75 \pm 187.19 \mathrm{ml}$ for the patients who did not. Table I shows the characteristics of the study patients.

\section{Factors Influencing Intraoperative Blood Loss}

Univariate linear regression analysis (Table 2) revealed that BMI, the number of involved discitis, levels of instrumentation, surgical approach and operative time were correlated with intraoperative blood loss. Moreover, multivariate linear regression analysis revealed that a higher $\mathrm{BMI}$, higher levels of instrumentation, a combined approach and a prolonged operative time were linked to higher intraoperative blood loss (Table 2). The results showed that the amount of blood loss increased as BMI increased $\left(18.42 \mathrm{~mL}\right.$ per $1 \mathrm{~kg} / \mathrm{m}^{2}$ increase in $\left.\mathrm{BMI}\right)$ and as operative time increased $(2.33 \mathrm{ml}$ per $1 \mathrm{~min}$ increase in operative time). In patients undergoing a combined surgical approach, the amount of blood loss increased by $325.78 \mathrm{ml}$. The amount of intraoperative blood loss was significantly higher $(514 \mathrm{ml}$ higher) in patients with four or more levels of instrumentation. 
Table 1

Characteristics of the Study Patients

\begin{tabular}{|c|c|c|c|}
\hline Characteristics & $\mathbf{N}$ & $\%$ & Mean \pm SD \\
\hline Age (Years old) & 336 & & $49.5 \pm 15.6$ \\
\hline \multicolumn{4}{|l|}{ Gender } \\
\hline Male & 158 & $47 \%$ & \\
\hline Female & 178 & $53 \%$ & \\
\hline BMI & & & $22.24 \pm 3.69$ \\
\hline Preoperative hemoglobin $(\mathrm{g} / \mathrm{L})$ & & & $122.04 \pm 17.37$ \\
\hline \multicolumn{4}{|l|}{ Location } \\
\hline Thoracic & 117 & 34.8 & \\
\hline Thoracolumbar & 15 & 4.5 & \\
\hline Lumbar/Lumbosacral & 204 & 60.7 & \\
\hline \multicolumn{4}{|l|}{ Vertebral collapse/Kyphosis } \\
\hline Without & 266 & $79.4 \%$ & \\
\hline With & 69 & $20.6 \%$ & \\
\hline \multicolumn{4}{|c|}{ Abscess (paravertebral or epidural) } \\
\hline Without & 99 & 29.5 & \\
\hline With & 237 & 70.5 & \\
\hline \multicolumn{4}{|l|}{ Levels of instrumentation } \\
\hline Two & 186 & $55.9 \%$ & \\
\hline Three & 67 & $20.1 \%$ & \\
\hline Four or more & 80 & $24.0 \%$ & \\
\hline \multicolumn{4}{|l|}{ Surgical approach } \\
\hline Anterior & 204 & $60.7 \%$ & \\
\hline Posterior & 109 & $32.4 \%$ & \\
\hline Combined & 23 & $6.8 \%$ & \\
\hline Operative time (minutes) & & & $244.98 \pm 107.51$ \\
\hline Intraoperative blood loss (ml) & & & $661.37 \pm 557.54$ \\
\hline
\end{tabular}




\begin{tabular}{|c|c|c|c|}
\hline Characteristics & $\mathbf{N}$ & $\%$ & Mean \pm SD \\
\hline Yes & 221 & $34.0 \%$ & \\
\hline No & 114 & $66.0 \%$ & \\
\hline
\end{tabular}


Table 2

Results of univariate and multivariate analysis to determine intraoperative blood loss among different exposure variables

\section{Univariate analysis Multivariate analysis}

$\begin{array}{lllll}\text { Variable } & \text { Regression } 95 \% \mathrm{Cl} & \mathrm{P} & \begin{array}{l}\text { Regression } 95 \% \mathrm{Cl} \\ \text { coefficient }\end{array} & \mathrm{P} \\ & & \text { coefficient } & \\ & (\beta) & & (\beta)\end{array}$

\begin{tabular}{lllllll} 
Age (years) & -1.51 & $-5.34-2.33$ & 0.44 & & \\
\hline Gender & & & & & \\
\hline Male & 1 & & & & & \\
\hline Female & 3.30 & $\begin{array}{l}-116.75- \\
123.36\end{array}$ & 0.96 & & \\
\hline $\begin{array}{l}\text { Preoperative hemoglobin } \\
\text { (g/L) }\end{array}$ & 1.28 & $-2.20-4.75$ & 0.47 & & $0.79-$ & 0.04 \\
\hline BMI & 30.24 & $\begin{array}{l}11.35- \\
49.13\end{array}$ & 0.002 & 18.416 & 36.04 & \\
\hline
\end{tabular}

\section{Location}

Thoracic

1

Thoracolumbar

64.86

$-225.20-$

0.66

354.92

Lumbar/Lumbosacral

$-116.91$

$-238.95-$

0.06

5.14

\section{Vertebral}

collapse/Kyphosis

Without

With

\section{Discitis}

One

Two

Three or more

Abscess (paravertebral or epidural)

1

49.71

-98.55-

197.98
0.51
(B) 


\begin{tabular}{|c|c|c|c|c|c|c|}
\hline & & \multicolumn{3}{|c|}{ Univariate analysis } & \multicolumn{2}{|c|}{ Multivariate analysis } \\
\hline Anterior & 1 & & & & & \\
\hline Posterior & 91.81 & $\begin{array}{l}-35.80- \\
219.42\end{array}$ & 0.158 & 124.82 & $\begin{array}{l}-3.92- \\
253.55\end{array}$ & 0.057 \\
\hline Combined & 282.30 & $\begin{array}{l}46.97- \\
517.64\end{array}$ & 0.019 & 325.77 & $\begin{array}{l}87.11- \\
564.43\end{array}$ & 0.008 \\
\hline \multicolumn{7}{|l|}{ Levels of instrumentation } \\
\hline Two & 1 & & & & & \\
\hline Three & 56.09 & $\begin{array}{l}-94.10- \\
206.28\end{array}$ & 0.463 & 245.11 & $\begin{array}{l}-17.58- \\
507.81\end{array}$ & 0.067 \\
\hline Four or more & 432.05 & $\begin{array}{l}298.97- \\
565.14\end{array}$ & $<.001$ & 536.54 & $\begin{array}{l}309.21- \\
763.88\end{array}$ & 0 \\
\hline Operative time (minutes) & 2.71 & $2.23-3.18$ & $<.001$ & 2.33 & $\begin{array}{l}1.64- \\
3.02\end{array}$ & $\begin{array}{l}<.001 \\
0.01\end{array}$ \\
\hline
\end{tabular}

Multivariable logistic regression analysis (Table 3) revealed five significant predictors of high intraoperative blood loss in the entire cohort. Next, we developed a tool that allows us to more accurately estimate the risk of high blood loss during surgery at an individual level. Nomograms were established by the multivariate logistic regression model according to all the significant variable factors. Figure 1 shows the nomogram predicting the risk of high amounts of intraoperative blood loss. The C-index of this nomogram is 0.784 (bootstrapped $95 \% \mathrm{Cl}[0.729-0.834]$ ). Figure 2 shows a calibration plot comparing the predicted probabilities of a high amount of intraoperative blood loss based on 228 bootstrapped samples. 
Table 3

Multivariable Logistic Regression Analysis to Identify Predictors of the high amount of intraoperative blood loss

\begin{tabular}{|lll|}
\hline Variable & Odds Ratio (95\% Cl) & $P$ \\
\hline Age (years) & $0.97(0.94-0.99)$ & 0.029 \\
\hline Gender & & \\
\hline Male & Ref. & \\
\hline Female & $1.13(1.57-2.23)$ & 0.718 \\
\hline Preoperative hemoglobin (g/L) & $0.97(0.95-1.00)$ & 0.031 \\
\hline BMI & $1.20(1.06-1.33)$ & 0.024 \\
\hline Location & & \\
\hline Thoracic & Ref. & \\
\hline Thoracolumbar & $0.35(0.07-1.78)$ & 0.207 \\
\hline Lumbar/Lumbosacral & $0.82(0.39-1.73)$ & 0.599 \\
\hline Vertebral collapse/Kyphosis & & 0.021 \\
\hline Without & Ref. & \\
\hline With & $1.33(0.59-2.97)$ & 0.494 \\
\hline Discitis & & \\
\hline One & & \\
\hline Two & & \\
\hline Three or more & & \\
\hline Abscess (paravertebral or epidural) & & 0.989 \\
\hline Without & Ref. & \\
\hline With & $0.68(0.34-1.40)$ & \\
\hline Levels of instrumentation & & \\
\hline Two & & \\
\hline Three & & \\
\hline Four or more & & \\
\hline Surgical approach & & \\
\hline Anterior & & \\
\hline
\end{tabular}




\begin{tabular}{|lll|}
\hline Variable & Odds Ratio (95\% Cl) & $P$ \\
\hline Posterior & $0.95(0.45-2.02)$ & 0.900 \\
\hline Combined & $0.91(0.28-3.02)$ & 0.886 \\
\hline Operative time (minutes) & $1.01(1.00-1.01)$ & 0.018 \\
\hline
\end{tabular}

\section{Predictors Of Perioperative Blood Transfusion}

In the univariate regression analysis (Table 4), the numbers of involved discitis, levels of instrumentation, the surgical approach, the operative time and the intraoperative blood loss were significantly associated with perioperative blood transfusion. Furthermore, multivariate logistic regression analysis was performed to adjust for interactions between covariates and identified four predictors of allogeneic blood transfusion in the perioperative period (Table 4). The risk of allogenic blood transfusion increased with female sex, vertebral collapse/kyphosis, and intraoperative blood loss. A higher BMI decreased the risk of allogeneic blood transfusion in patients. 
Table 4

Univariate and Multivariate Logistic Regression Analysis to Identify Predictors of Perioperative Blood Transfusion

\begin{tabular}{|c|c|c|c|c|}
\hline \multirow[t]{3}{*}{ Variable } & \multicolumn{4}{|c|}{ Perioperative Blood Transfusion } \\
\hline & \multicolumn{2}{|l|}{ Univariate analysis } & \multicolumn{2}{|c|}{ Multivariate analysis } \\
\hline & OR $(95 \% \mathrm{Cl})$ & $P$ & OR $(95 \% \mathrm{Cl})$ & $P$ \\
\hline Age (years) & $1.00(0.99-1.02)$ & 0.797 & $1.02(0.98-1.68)$ & 0.233 \\
\hline \multicolumn{5}{|l|}{ Gender } \\
\hline Male & Ref. & & Ref. & \\
\hline Female & $1.50(0.95-2.36)$ & 0.081 & $4.59(1.56-13.47)$ & 0.006 \\
\hline Preoperative hemoglobin $(\mathrm{g} / \mathrm{L})$ & $0.99(0.98-1.01)$ & 0.791 & $1.01(0.98-1.03)$ & 0.455 \\
\hline BMI & $0.71(0.91-1.06)$ & 0.709 & $0.84(0.71-0.99)$ & 0.039 \\
\hline \multicolumn{5}{|l|}{ Location } \\
\hline Thoracic & Ref. & & Ref. & \\
\hline Thoracolumbar & $0.86(0.67-1.10)$ & 0.17 & $4.07(0.38-44.14)$ & 0.250 \\
\hline Lumbar/Lumbosacral & $0.76(0.47-1.23)$ & 0.26 & $1.43(0.50-4.11)$ & 0.501 \\
\hline \multicolumn{5}{|l|}{ Vertebral collapse/Kyphosis } \\
\hline Without & Ref. & & Ref. & \\
\hline With & $1.13(0.64-1.99)$ & 0.673 & $4.74(1.34-16.79)$ & 0.016 \\
\hline \multicolumn{5}{|l|}{ Discitis } \\
\hline One & Ref & & Ref & \\
\hline Two & $2.02(1.11-3.70)$ & 0.020 & $1.00(0.12-8.73)$ & 0.705 \\
\hline Three or more & $2.83(1.35-5.97)$ & 0.006 & $1.34(0.18-10.12)$ & 0.997 \\
\hline \multicolumn{5}{|l|}{ Levels of instrumentation } \\
\hline Two & Ref. & & Ref. & \\
\hline Three & $2.37(1.27-4.41)$ & 0.007 & $3.92(0.70-22.15)$ & 0.121 \\
\hline Four or more & $4.57(2.31-8.99)$ & $<0.001$ & $3.27(0.18-59.30)$ & 0.424 \\
\hline \multicolumn{5}{|c|}{ Abscess (paravertebral or epidural) } \\
\hline Without & Ref. & & Ref. & \\
\hline With & $0.96(0.58-1.57)$ & 0.862 & $0.48(0.16-1.41)$ & 0.183 \\
\hline
\end{tabular}




\begin{tabular}{|lllll|}
\hline Variable & \multicolumn{4}{l|}{ Perioperative Blood Transfusion } \\
\hline Approach & \multicolumn{4}{l}{} \\
\hline Anterior & Ref. & \multicolumn{2}{l|}{ Ref. } & \\
\hline Posterior & $1.49(0.91-2.46)$ & 0.11 & $0.88(0.06-14.19)$ & 0.933 \\
\hline Combined & $14.3(1.89-108.26)$ & 0.01 & $0.92(0.06-14.47)$ & 0.928 \\
\hline Operative time (minutes) & $1.01(1.00-1.02)$ & $<0.001$ & $1.00(0.99-1.01)$ & 0.486 \\
\hline Intraoperative Blood Loss (ml) & $1.01(1.01-1.01)$ & $<0.001$ & $1.01(0.98-1.03)$ & $<0.001$ \\
\hline
\end{tabular}

\section{Discussion}

During surgery for spinal tuberculosis infection, patients can lose a significant amount of blood, which may result in the patient receiving a blood transfusion. Therefore, it is important to evaluate the different risk factors for increased intraoperative blood loss and perioperative blood transfusion, which can potentially be used for preoperative planning and risk stratification to evaluate outcomes.

Through autologous blood transfusion contributing to reducing perioperative blood loss, the fact that spinal tuberculosis or brucellosis is a complication of a systematic disease makes it impossible to perform preoperative autologous blood donation and intraoperative autologous blood transfusion. Several previous studies have investigated risk factors associated with the risk of transfusion in spine surgical patient populations. In lumbar fusion surgery, ASA $>1$, prolonged operative time, multilevel fusion, sacrum involvement, and open posterior approach are predictors of transfusion.[13] Similarly, Durand reported that operative duration, surgical invasiveness, hematocrit, weight, and age were the most influential variables for predicting blood transfusion.[14] In addition, it has been reported that preoperative hemoglobin levels are an important predictor of allogenic blood transfusion in the perioperative period for patients who underwent surgery. However, in our analysis, preoperative hemoglobin levels did not predict the need for a perioperative blood transfusion among patients with spinal tuberculosis. Our data also revealed that the preoperative hemoglobin levels were significantly correlated with high intraoperative blood loss. Preoperative low hemoglobin levels may increase postoperative complications for patients with spinal tuberculosis.[18] In addition, several studies have shown that preoperative anemia is associated with poor outcomes after surgery and increased health care use. $[19,20]$ Therefore, the correction of preoperative anemia may improve the outcome of spinal tuberculosis surgery.

Several clinical factors, including the higher number of involved discitis, higher levels of instrumentation and combined surgical approach, were found to be correlated with the increased rate of blood transfusion and intraoperative blood loss. However, after adjusting for interactions between covariates in the 
multivariate analysis, the influence of these factors was revealed to be nonsignificant, and the odds of transfusion increased by 4.5 times when patients had a pathological fracture or kyphosis. The choice of surgical approach has been reported to be linked to intraoperative blood loss.[21, 22] Previous studies reported that one-stage anterior operation had advantages when compared to posterior instrumentation, as both instrumentation and grafting are performed as single-stage surgery through the same incision, which may minimize total blood loss.[21, 23] In contrast, other studies illustrated that the posterior approach favors less intraoperative blood loss. This difference may be attributed to the preference and experience of surgeons. Usually, the combined approach often leads to prolonged operative time and more blood loss, which may be associated with significant kyphosis and multiple-level lesions.[24] Furthermore, our investigation revealed that increased operative time is strongly associated with a higher likelihood of blood transfusion and a higher amount of blood loss. Four or more levels of instrumentation are also a risk factor for high intraoperative blood loss. In fact, operating time and blood loss are associated with an increase in the number of levels fused or instrumentation in spine surgery.[13, 25] Kumar reported the results of their review of 243 patients undergoing surgery for metastatic spinal tumors and identified primary tumor, type of surgery, and prolonged surgery time as predictors of increased blood loss.[25]

Our results showed that female sex and lower BMI were risk factors for blood transfusion. A possible explanation for the relationships between blood transfusion and gender and BMI is that a smaller body size may increase intraoperative blood loss. [26] In our cohort, the mean age was $49.5 \pm 15.6$ years old. In North America, Europe and China, tuberculous spondylodiscitis is more commonly seen in adult patients with a mean age of 40 years $[1,27]$. It has been reported that advanced age did not increase the morbidity associated with spinal operation.[28] For most patients, robust compensatory mechanisms render hypotension an insensitive indicator of shock until more than $30 \%$ of the patient's blood volume has been lost; therefore, intraoperative blood loss over $30 \%$ of the total blood volume was set as the cutoff in this study. Intraoperative cues indicative of intraoperative blood transfusion include low hematocrit and hemoglobin levels (<70 g/L), a higher heart rate (> 120 beats $/ \mathrm{min})$, a weak peripheral pulse, and cool extremities with pale or mottled skin, among others.[29]

Several factors probably contribute to reducing the risk of bleeding during spinal tuberculosis surgery. Proper surgical approaches, the discontinuation of anticoagulant medications, the correction of preoperative anemia and the preoperative estimation of blood loss are essential in minimizing blood loss in surgery[30]. Intraoperative methods to control blood loss include positioning to reduce intraabdominal pressure, the use of tranexamic acid and the use of topical antifibrinolytic agents. Moreover, modified anesthesia techniques such as core temperature control and hypotensive anesthesia have shown promising results in safely reducing blood loss[30-32].

There were several limitations in this study. This was a retrospective study with a small sample size. A multicenter study should be conducted. Almost all the patients in this cohort had spondylodiscitis. Patients with atypical forms of spondylitis without disc involvement were not included in this study. There was also a lack of clinical information on commodities, medications, nutritional status and other 
variables. Tranexamic acid was not given to patients in this cohort; therefore, its effect on spinal tuberculosis surgery was not evaluated. It has been reported that tranexamic acid could reduce both intraoperative-perioperative allogeneic transfusion rates and operative time in spinal surgeries.[33] A recent study demonstrated that tranexamic acid contributes to reducing the drainage and blood transfusion perioperative duration of tuberculosis patients, but it cannot decrease intraoperative blood loss.[34] The cause of transfusion was also not collected, but patients typically get transfused when their hemoglobin level less than $70 \mathrm{~g} / \mathrm{L}$, and they present changes in symptomatic or vital signs. Additionally, the risk of bleeding with regards to other causes of spine surgery was not investigated and a such comparation would be further analyzed in future work. However, despite such limitations, we believe that we assessed several important clinical variables that allowed us to determine the relationships between the evaluated surgeries and blood loss and the risk of blood transfusions.

\section{Conclusions}

In conclusion, the findings of this study have substantial implications for perioperative management in patients with spinal tuberculosis. Our study revealed a significant relationship between blood transfusions and female gender, BMl, vertebral collapse/kyphosis and intraoperative blood loss. Furthermore, a lower BMI, decreased preoperative hemoglobin levels, four or more levels of instrumentation, a combined surgical approach and a prolonged operative time were identified as risk factors for high levels of intraoperative blood loss. An understanding of these factors may contribute to preoperative planning and help to minimize postoperative complications.

\section{Declarations}

\section{Ethics approval and consent to participate}

This study was approved by the Medical Ethics Committee of the second affiliated Hospital of Harbin Medical University, Heilongjiang. A certificate of approval has been provided. Due to the retrospective nature of the study, formal informed consent from the participants was not required.

\section{Consent to publish}

Not applicable.

\section{Availability of data and materials}

The datasets analysed during the current study are available from the corresponding author on reasonable request.

\section{Competing interests}

The authors declare that they have no competing interests. 


\section{Funding}

This work supported by the Fund of HMU-2nd Affiliated Hospital for Outstanding Young Scholars (Wang, YuFu), the Fundamental Research Fund for Universities in Heilongjiang Province (Wang, Shengyu) and the Scientific research project of Heilongjiang Health Committee $₫ 2016-077 \rrbracket W a n g$, Shengyu $\rrbracket$.

\section{Authors' Contributions}

SYW, CL and CCS: Conducted the study. Collected, analyzed and interpreted the data. YFW and JLY: Designed the study and interpreted the data. RZW, QHZ and FW: Statistical analyzed and interpreted the data. YFW and SYW: Wrote the paper. All the authors read and approved the final manuscript.

\section{Acknowledgements}

Not applicable.

\section{References}

1. Skaf GS, Kanafani ZA, Araj GF, Kanj SS: Non-pyogenic infections of the spine. International journal of antimicrobial agents 2010, 36(2):99-105.

2. Pellise F: Tuberculosis and Pott's disease, still very relevant health problems. European spine journal : official publication of the European Spine Society, the European Spinal Deformity Society, and the European Section of the Cervical Spine Research Society 2013, 22 Suppl 4:527-528.

3. Dunn RN, Ben Husien M: Spinal tuberculosis. The bone \& joint journal 2018, 100-B(4):425-431.

4. Chen Y, Yang JS, Li T, Liu P, Liu TJ, He LM, Qian LX, Hao DJ: One-stage Surgical Management for Lumbar Brucella Spondylitis by Posterior Debridement, Autogenous Bone Graft and Instrumentation: A Case Series of 24 Patients. Spine 2017, 42(19):E1112-E1118.

5. Li L, Xu J, Ma Y, Tang D, Chen Y, Luo F, Li D, Hou T, Zhou Q, Dai F et al: Surgical strategy and management outcomes for adjacent multisegmental spinal tuberculosis: a retrospective study of forty-eight patients. Spine 2014, 39(1):E40-48.

6. Dai LY, Jiang LS, Wang W, Cui YM: Single-stage anterior autogenous bone grafting and instrumentation in the surgical management of spinal tuberculosis. Spine 2005, 30(20):2342-2349.

7. Ulu-Kilic A, Karakas A, Erdem H, Turker T, Inal AS, Ak O, Turan H, Kazak E, Inan A, Duygu F et al: Update on treatment options for spinal brucellosis. Clinical microbiology and infection : the official publication of the European Society of Clinical Microbiology and Infectious Diseases 2014, 20(2):075-82.

8. Jin W, Wang Q, Wang Z, Geng G: Complete debridement for treatment of thoracolumbar spinal tuberculosis: a clinical curative effect observation. The spine journal : official journal of the North American Spine Society 2014, 14(6):964-970. 
9. Yin XH, Liu SH, Li JS, Chen Y, Hu XK, Zeng KF, Yu HG, Zhou ZH, Zhang HQ: The role of costotransverse radical debridement, fusion and postural drainage in the surgical treatment of multisegmental thoracic spinal tuberculosis: a minimum 5-year follow-up. European spine journal : official publication of the European Spine Society, the European Spinal Deformity Society, and the European Section of the Cervical Spine Research Society 2016, 25(4):1047-1055.

10. Wang LJ, Zhang HQ, Tang MX, Gao QL, Zhou ZH, Yin XH: Comparison of Three Surgical Approaches for Thoracic Spinal Tuberculosis in Adult: Minimum 5-Year Follow Up. Spine 2017, 42(11):808-817.

11. Janssen SJ, Braun Y, Wood KB, Cha TD, Schwab JH: Allogeneic blood transfusions and postoperative infections after lumbar spine surgery. The spine journal : official journal of the North American Spine Society 2015, 15(5):901-909.

12. Basques BA, Fu MC, Buerba RA, BohI DD, Golinvaux NS, Grauer JN: Using the ACS-NSQIP to identify factors affecting hospital length of stay after elective posterior lumbar fusion. Spine 2014, 39(6):497502.

13. Morcos MW, Jiang F, McIntosh G, Johnson M, Christie S, Wai E, Ouellet J, Bailey C, Ahn H, Paquet J et al: Predictors of Blood Transfusion in Posterior Lumbar Spinal Fusion: A Canadian Spine Outcome and Research Network Study. Spine 2018, 43(1):E35-E39.

14. Durand WM, DePasse JM, Daniels AH: Predictive Modeling for Blood Transfusion After Adult Spinal Deformity Surgery: A Tree-Based Machine Learning Approach. Spine 2018, 43(15):1058-1066.

15. Park JH, Rasouli MR, Mortazavi SM, Tokarski AT, Maltenfort MG, Parvizi J: Predictors of perioperative blood loss in total joint arthroplasty. The Journal of bone and joint surgery American volume 2013, 95(19):1777-1783.

16. Erdem H, Elaldi N, Batirel A, Aliyu S, Sengoz G, Pehlivanoglu F, Ramosaco E, Gulsun S, Tekin R, Mete B et al: Comparison of brucellar and tuberculous spondylodiscitis patients: results of the multicenter "Backbone-1 Study". The spine journal : official journal of the North American Spine Society 2015, 15(12):2509-2517.

17. Carling MS, Jeppsson A, Eriksson BI, Brisby H: Transfusions and blood loss in total hip and knee arthroplasty: a prospective observational study. Journal of orthopaedic surgery and research 2015 , 10:48.

18. Yanhua; C, Juan; L, Zixian; C, Xiaogang; Z, Jian D: Risk factors analysis of the postoperative complications in spinal tuberculosis patients. Chinese Journal of Orthopaedics 2016, 36(17):11261132.

19. Fowler AJ, Ahmad T, Phull MK, Allard S, Gillies MA, Pearse RM: Meta-analysis of the association between preoperative anaemia and mortality after surgery. The British journal of surgery 2015 , 102(11):1314-1324.

20. Elsamadicy AA, Adogwa O, Ongele M, Sergesketter AR, Tarnasky A, Lubkin DET, Drysdale N, Cheng J, Bagley CA, Karikari IO: Preoperative Hemoglobin Level is Associated with Increased Health Care Use After Elective Spinal Fusion ( $>=3$ Levels) in Elderly Male Patients with Spine Deformity. World neurosurgery 2018, 112:E348-E354. 
21. Yang P, Zang Q, Kang J, Li H, He X: Comparison of clinical efficacy and safety among three surgical approaches for the treatment of spinal tuberculosis: a meta-analysis. European spine journal: official publication of the European Spine Society, the European Spinal Deformity Society, and the European Section of the Cervical Spine Research Society 2016, 25(12):3862-3874.

22. Wang $X$, Pang $X$, Wu P, Luo $C$, Shen $X$ : One-stage anterior debridement, bone grafting and posterior instrumentation vs. single posterior debridement, bone grafting, and instrumentation for the treatment of thoracic and lumbar spinal tuberculosis. European spine journal : official publication of the European Spine Society, the European Spinal Deformity Society, and the European Section of the Cervical Spine Research Society 2014, 23(4):830-837.

23. Hassan K, Elmorshidy E: Anterior versus posterior approach in surgical treatment of tuberculous spondylodiscitis of thoracic and lumbar spine. European spine journal : official publication of the European Spine Society, the European Spinal Deformity Society, and the European Section of the Cervical Spine Research Society 2016, 25(4):1056-1063.

24. Qureshi MA, Khalique AB, Afzal W, Pasha IF, Aebi M: Surgical management of contiguous multilevel thoracolumbar tuberculous spondylitis. European spine journal : official publication of the European Spine Society, the European Spinal Deformity Society, and the European Section of the Cervical Spine Research Society 2013, 22 Suppl 4:618-623.

25. Kumar N, Zaw AS, Khine HE, Maharajan K, Wai KL, Tan B, Mastura S, Goy R: Blood Loss and Transfusion Requirements in Metastatic Spinal Tumor Surgery: Evaluation of Influencing Factors. Annals of surgical oncology 2016, 23(6):2079-2086.

26. Jain A, Sponseller PD, Newton PO, Shah SA, Cahill PJ, Njoku DB, Betz RR, Samdani AF, Bastrom TP, Marks MC: Smaller body size increases the percentage of blood volume lost during posterior spinal arthrodesis. The Journal of bone and joint surgery American volume 2015, 97(6):507-511.

27. Wang H, Li C, Wang J, Zhang Z, Zhou Y: Characteristics of patients with spinal tuberculosis: sevenyear experience of a teaching hospital in Southwest China. International orthopaedics 2012, 36(7):1429-1434.

28. Ragab AA, Fye MA, Bohlman HH: Surgery of the lumbar spine for spinal stenosis in 118 patients 70 years of age or older. Spine 2003, 28(4):348-353.

29. Cannon JW: Hemorrhagic Shock. The New England journal of medicine 2018, 378(4):370-379.

30. Bible JE, Mirza M, Knaub MA: Blood-loss Management in Spine Surgery. J Am Acad Orthop Surg 2018, 26(2):35-44.

31. Qureshi R, Puvanesarajah V, Jain A, Hassanzadeh H: Perioperative Management of Blood Loss in Spine Surgery. Clin Spine Surg 2017, 30(9):383-388.

32. Mikhail C, Pennington Z, Arnold PM, Brodke DS, Chapman JR, Chutkan N, Daubs MD, DeVine JG, Fehlings MG, Gelb DE et al: Minimizing Blood Loss in Spine Surgery. Global Spine J 2020, 10(1 Suppl):71S-83S.

33. Hui S, Xu D, Ren Z, Chen X, Sheng L, Zhuang Q, Li S: Can tranexamic acid conserve blood and save operative time in spinal surgeries? A meta-analysis. The spine journal : official journal of the North 
American Spine Society 2018, 18(8):1325-1337.

34. Geng $\unrhd \mathrm{T}$, Chen; $Y$, Zhang L: Safety and efficacy of tranexamic acid in the application of spinal tuberculosis surgery. Int J Clin Exp Med 2017, 10(2):7.

\section{Figures}

Points

Age (years old)

Operative time (minutes)

Levels of the Instrumentation

Preoperative Hemoglbin (g/L)

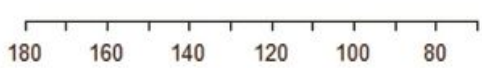

BMI

Total Points

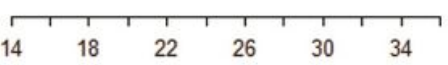$$
0
$$

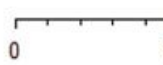

Predicted Possibility

3

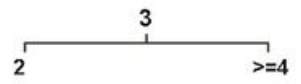

$\sqrt{-10}$

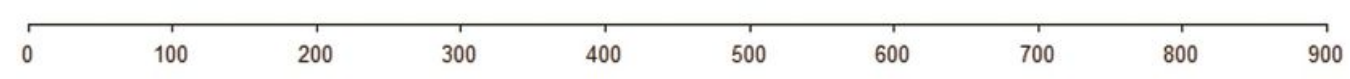

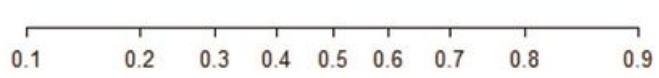

\section{Figure 1}

The prediction nomogram of the high amount of intraoperative blood loss. The nomogram is used by adding up the points identified on the points scale for each predictor. According to the sum of these points projected on the bottom scales, the nomogram can provide the predicted probability for intraoperative high blood loss. 


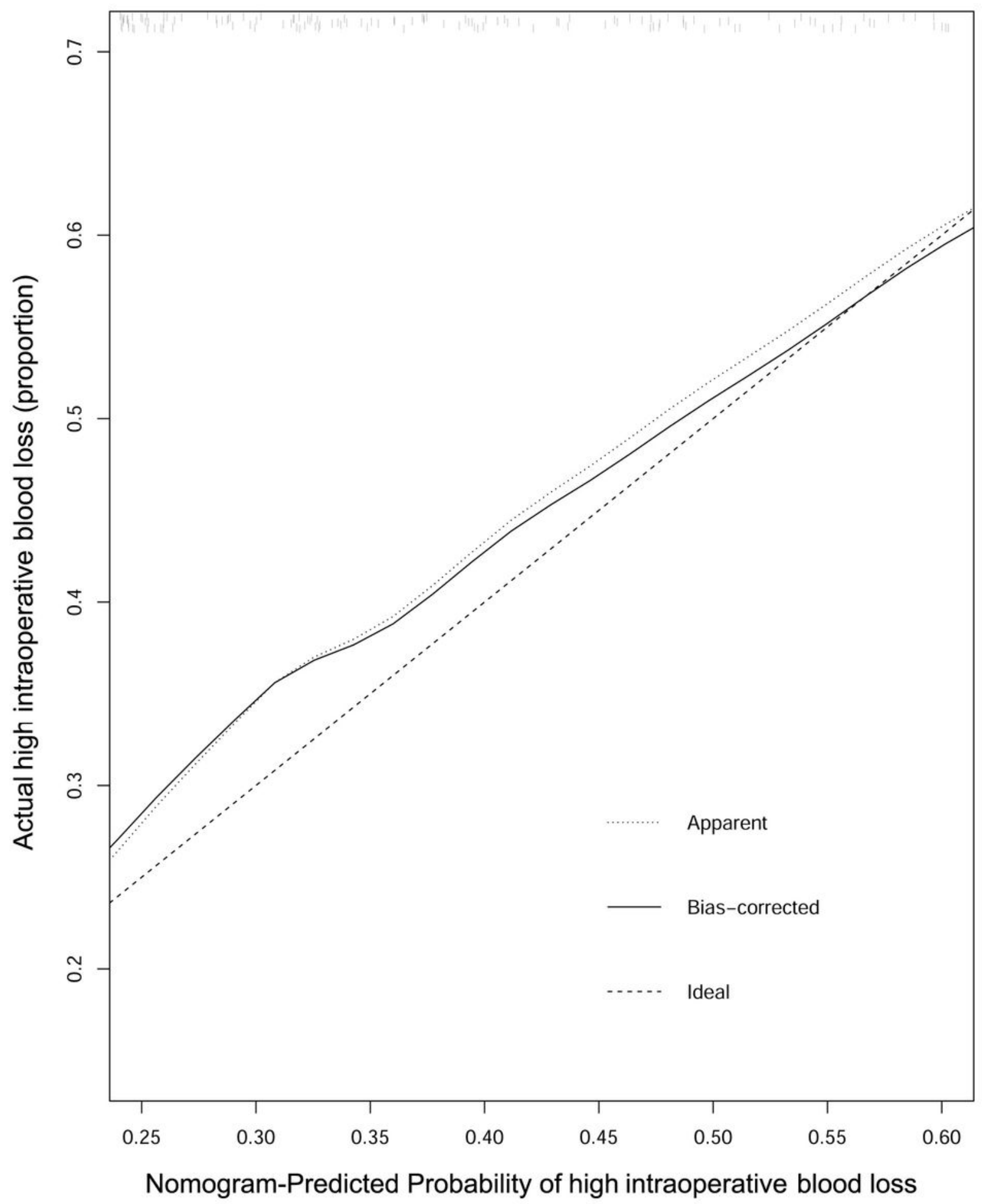

Figure 2

Bootstrap calibration plot showing actual versus predicted probability of intraoperative high blood loss. (Bootstrap samples=228) 